\title{
ConWin: Uma Ferramenta para Auxílio à Aprendizagem do Controle de Congestionamento TCP
}

\author{
Helcio Wagner da Silva
}

\author{
Departamento de Computação - Universidade Federal Rural do Semi-Árido (UFERSA) \\ Caixa Postal 59.625-900 - Mossoró - RN - Brasil \\ helciodufersa.edu.br
}

\begin{abstract}
The TCP congestion control is a topic that takes part in the Computer Networks discipline. It is a procedure composed of concepts and rules whose understanding has been seen difficult to be acquired by students. This paper presents an educacional game named ConWin, developed to improve the learning of that topic. Its goal is transfer a file as fast as possible by simulating driving a vehicle. The game was evaluated using the EGameFlow methodology and positive results have been obtained-especially on perception of improvement of learning.
\end{abstract}

Resumo. Um dos conteúdos que fazem parte da disciplina Redes de Computadores é o controle de congestionamento TCP. Trata-se de um procedimento composto por conceitos e regras cuja compreensão por vezes tem se mostrado dificil por parte dos alunos. Este artigo apresenta um jogo educacional denominado ConWin, desenvolvido para auxílio no aprendizado deste conteúdo. Seu objetivo é a transferência de um arquivo no menor tempo possivel, tendo como pano de fundo a condução de um veículo. O jogo foi avaliado utilizando a metodologia EGameFlow e obteve resultados muito positivos, principalmente na percepção da melhoria da aprendizagem.

\section{Introdução}

O TCP (Transmission Control Protocol) é um dos protocolos mais importantes da Internet. Ele provê um serviço de entrega confiável de dados que é necessário em muitos serviços populares, tais como navegação Web, download/upload de arquivos e transmissão de mensagens de correio eletrônico. Para prestar o seu serviço de maneira eficiente, o TCP realiza um conjunto de procedimentos. Dentre eles está o controle de congestionamento, que consiste basicamente na adaptação da taxa de transmissão às condições variantes de congestionamento. Trata-se de um dos conteúdos da disciplina "Redes de Computadores", presente na maior parte dos cursos de nível superior em Computação no Brasil. Embora seja farto o material sobre este conteúdo, foi observado localmente que os alunos comumente erram as questões sobre ele.

Por outro lado, estudos conduzidos por Vogel et al (2006) e Hays (2005) revisam e analisam vários outros estudos realizados sobre a aplicabilidade de jogos em ambientes instrucionais. De acordo com Vogel et al (2006), a utilização de jogos estimula a elevação dos níveis cognitivos, principalmente quando os aprendizes podem utilizá-los livremente - isto é, sem a supervisão dos instrutores. Já Hays (2005) destaca que a efetividade dos jogos não pode ser generalizada; a sua utilização deve ser baseada em uma análise detalhada das necessidades de aprendizagem e balanceada entre abordagens instrucionais alternativas. Além disso, aquele estudo conclui que suporte 
instrucional aumenta a sua efetividade. Os jogos voltados à instrução são denominados jogos sérios, de acordo com Michael e Chen (2005). É neste contexto que foi concebido o projeto e desenvolvimento de um jogo que auxilie na aprendizagem do controle de congestionamento TCP. De sorte a melhor apresentá-lo, este artigo é assim estruturado: a próxima seção descreve os fundamentos do controle de congestionamento TCP. A Seção 3 explica porque um jogo pode ser útil para auxiliar o seu ensino. A Seção 4 descreve a solução desenvolvida, e a Seção 5 aborda seu processo de validação. A Seção 6 realiza as considerações finais acerca do trabalho realizado.

\section{O Controle de Congestionamento TCP}

Para atingir taxas elevadas de transmissão, o TCP transmite vários de seus segmentos em rajadas. O tamanho desta rajada é denominado janela de congestionamento. Quanto maior for seu valor, maior será a taxa de transmissão. A Figura 1 ilustra um exemplo de como a janela pode variar ao longo das rodadas de transmissão. De acordo com Allman et at (1999), a janela de congestionamento parte inicialmente de um e cresce exponencialmente, dobrando a cada rodada de transmissão até atingir um valor denominado limiar. Na Figura 1, o valor inicial do limiar é de oito segmentos. Após atingir o limiar a janela passa a crescer linearmente, aumentando a cada rodada, até a perda de um dos segmentos transmitidos. Esta perda é normalmente vinculada ao descarte do datagrama que o encapsula em um roteador congestionado.

A perda pode ser percebida pela entidade TCP remetente de duas formas: pela recepção de três segmentos cujos números de reconhecimento são duplicados, ou pela expiração do temporizador de retransmissão associado ao segmento. A percepção da perda através da recepção de três segmentos com números de reconhecimento duplicados é uma forma de acelerar a retransmissão do segmento perdido, antes da expiração do seu temporizador de retransmissão associado. É este tipo de percepção que ocorre na $13^{\mathrm{a}}$ rodada de transmissão na Figura 1. Eventualmente, porém, o percurso pode estar tão congestionado que nem aqueles três segmentos chegam à entidade TCP remetente. É o que acontece na $20^{\text {a }}$ rodada de transmissão na Figura 1. Independentemente de como a perda é percebida, um novo valor para o limiar é definido como sendo a metade do valor da janela no qual a perda foi percebida.

A dinâmica da janela de congestionamento após uma perda depende de como ela foi percebida. Se a percepção se dá pela recepção de três segmentos com números de reconhecimentos duplicados, a janela diminui para o novo valor do limiar e passa a crescer linearmente até que ocorra uma nova perda - é o que ocorre na $13^{\mathrm{a}}$ rodada de transmissão na Figura 1. Por outro lado, se a percepção se dá pela expiração do temporizador de retransmissão associado ao segmento perdido, a janela despenca para o valor de um e cresce exponencialmente até atingir o novo valor do limiar - é o que ocorre na $20^{\mathrm{a}}$ rodada de transmissão na Figura 1. A partir daquele valor, ela passa a crescer linearmente até que ocorra uma nova perda.

Portanto, o controle de congestionamento TCP adapta a taxa de transmissão às condições de congestionamento ao longo do percurso. Quando o percurso se torna congestionado, os segmentos são transmitidos a uma taxa menor; quando as condições de congestionamento melhoram, a taxa de transmissão aumenta. A depender da gravidade do congestionamento, o valor da janela de congestionamento cai para a metade do seu valor anterior ou despenca para um. 


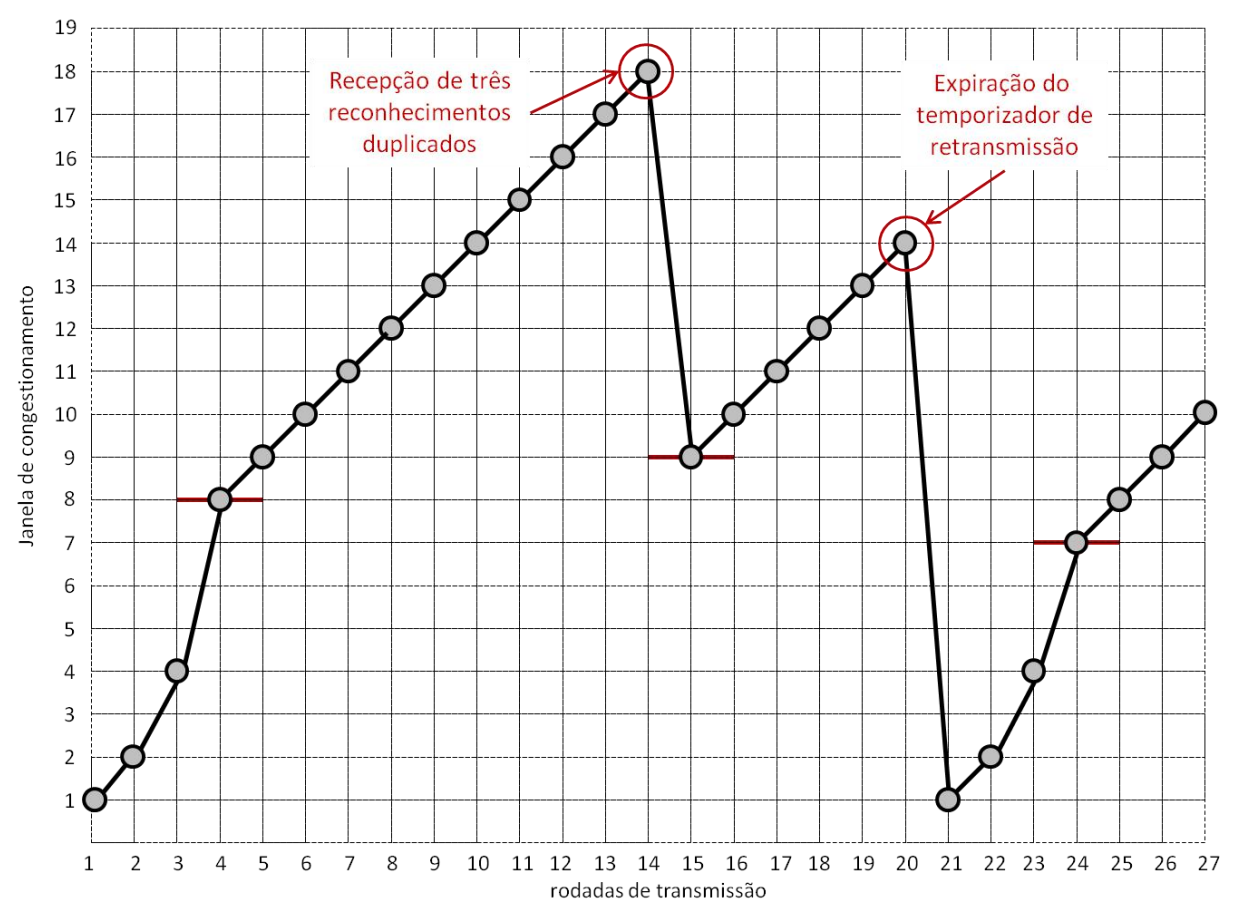

Figura 1. Exemplo de evolução da janela de congestionamento TCP

\section{A Necessidade de uma Ferramenta de Auxílio à Aprendizagem}

O controle de congestionamento TCP é um conteúdo abordado na disciplina "Redes de Computadores", comum em grades de cursos de Bacharelado e Licenciatura em computação ao longo do País. No curso de bacharelado em Ciência da Computação na Universidade Federal Rural do Semi-Árido (UFERSA), tem sido constatado que os estudantes possuem dificuldades na assimilação deste conteúdo. Esta constatação toma como base as notas obtidas em avaliações, especificamente nas questões que envolvem o assunto. Há basicamente duas variantes destas questões:

A primeira variante toma com base um gráfico semelhante àquele ilustrado pela Figura 1, e pede para o aluno identificar em quais rodadas de transmissão ocorrem as perdas e como elas são percebidas pela entidade TCP remetente. Esta variante objetiva a avaliação da aprendizagem dos conceitos de janela de congestionamento, limiar e percepção de perdas. Avalia também a aprendizagem dos princípios que constituem as relações entre aqueles conceitos. Pedagogicamente, a existência desta variante de questão ampara-se no fato de que, conforme afirma Zabala (1998), a aprendizagem de conceitos e princípios vai muito além da mera repetição, requerendo interpretações em situações práticas.

A segunda variante pede para o aluno traçar um gráfico semelhante àquele ilustrado pela Figura 1, sendo fornecidos o valor inicial do limiar, as rodadas de transmissão em ocorrem as perdas e como elas são percebidas pela entidade TCP remetente. Supõe adicionalmente que a janela de congestionamento inicia-se em um. Esta variante solicita a construção do gráfico por entender que, de acordo com Zabala (1998) a aprendizagem de um procedimento requer a realização de suas respectivas ações. Por exigir contínua reflexão sobre a própria atividade, não é de se estranhar que ela é quem possua a menor quantidade de acertos dentre as duas variantes. 
Não obstante o farto material sobre o assunto, os alunos comumente erram aquelas questões. Esta constatação levou à busca de soluções complementares à tradicional. Em Batistella e Wangenheim (2016) é realizada uma revisão sistemática do uso de jogos no ensino superior das várias áreas da Computação. Os autores afirmam que os jogos examinados referentes à área de Redes de Computadores são tipicamente voltados à simulação de cenários realistas nos quais a tarefa do jogador é identificar problemas em sub-redes e resolvê-los. De fato, a adoção do NS-2 [NS2 Simulator Projects 2018] seria uma alternativa para mitigação deste problema de assimilação do conteúdo relativo ao controle de congestionamento TCP. Porém, o NS é uma ferramenta de simulação de espectro amplo - isto é, ela não é dedicada a nenhum protocolo em particular, mas a uma gama deles. Sua instalação é por vezes não trivial, e seu uso requer o conhecimento de uma linguagem de programação específica (Tcl/Tk) para a construção de cenários a serem simulados. Apesar de mais jogos educativos terem sido desenvolvidos desde então, nenhum deles aborda especificamente o controle de congestionamento TCP. Neste contexto, optou-se por desenvolver um jogo para auxílio na aprendizagem deste conteúdo.

\section{A Ferramenta Desenvolvida}

A ferramenta desenvolvida para apoio à aprendizagem é um jogo sério que recebeu o nome de ConWin, uma abreviatura conhecida de Congestion Window - ou "janela de congestionamento". O jogo foi desenvolvido utilizando o engine Unity, e uma versão para a Web está acessível no URL https://conwin.000webhostapp.com/. A Figura 2 ilustra o desenrolar de uma partida. O jogo tem como pano de fundo a transferência de um arquivo em partes encapsuladas por segmentos TCP. O progresso desta transferência é indicado por uma barra horizontal (1) e o objetivo do jogo é realizá-la no menor tempo possível, marcado em (2). O jogador faz isto de maneira lúdica imaginando-se na condução de um veículo. Para tal, quando o semáforo indica condição de tráfego livre com sua luz verde ativada (3), ele engata a marcha na posição DRIVE (4) e aciona o acelerador (5), fazendo com que um avatar representando a janela de congestionamento (6) evolua ao longo das rodadas de transmissão. Quando o veículo está em movimento, ele pode ver a paisagem passando por uma janela (7). Um indicador (8) registra o valor instantâneo da janela de congestionamento. Os intervalos de 24 rodadas se sucedem, a janela iniciando o próximo intervalo com o valor em que terminou o último. $\mathrm{O}$ jogo permite que o jogador se identifique, tenha uma breve explicação sobre sua dinâmica e visualize os cinco melhores tempos obtidos.

Durante a evolução da janela de congestionamento, situações de perda de segmento ocorrem aleatoriamente, tanto do ponto de vista da rodada em que acontecem quanto da forma como são percebidas. Na Figura 3, a recepção de três reconhecimentos duplicados é modelada pela alteração na imagem do avatar (1), pelo acendimento da luz amarela do semáforo (2) e pela presença de um conjunto de veículos na janela de observação bloqueando o deslocamento do veículo do jogador (3). As ações a serem realizadas pelo jogador nestas circunstâncias, não ilustradas pela figura, são engatar a marcha na posição "3 ACKs" e acelerar até que o avatar atinja o novo limiar. Neste ponto, a imagem do avatar voltará ao estado anterior e a luz do semáforo acesa voltará a ser a verde. A partir daí, o jogador deve engatar a marcha na posição "DRIVE" e acelerar para que a janela de congestionamento volte a crescer. Quanto mais rápido as ações forem realizadas, menor será o tempo de descarregamento do arquivo. 


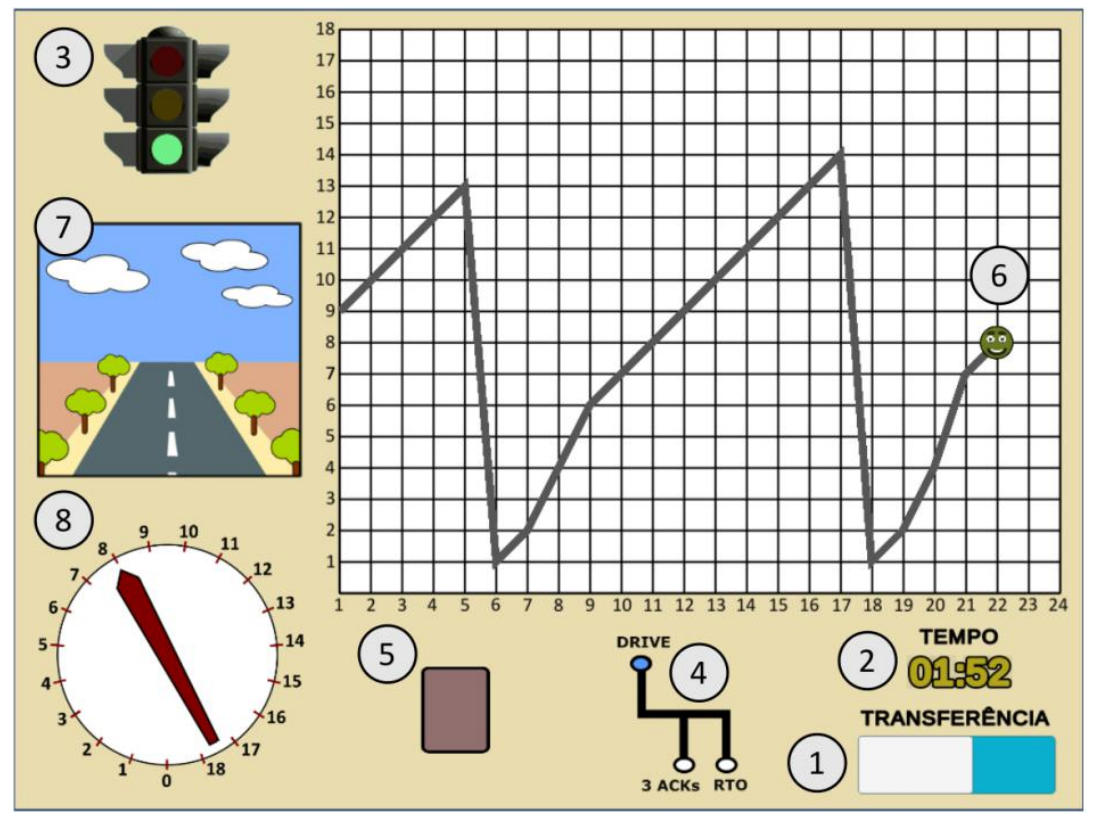

Figura 2. Tela do jogo em execução.

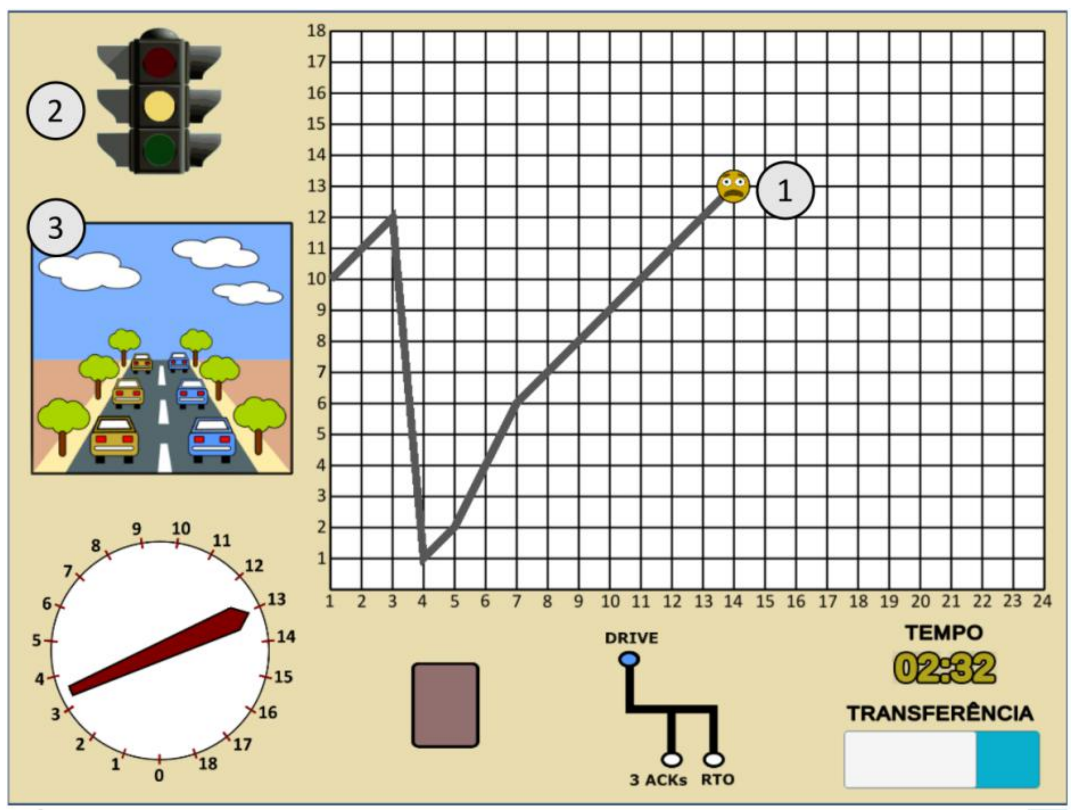

Figura 3. Perda percebida pela recepção de três reconhecimentos duplicados

Na Figura 4, a percepção de uma perda devido à expiração do temporizador de retransmissão é modelada pela alteração na imagem do avatar (1), pelo acendimento da luz amarela do semáforo (2) e pela presença de um conjunto de veículos na janela de observação bloqueando o deslocamento do veículo do jogador (3). As ações a serem realizadas pelo jogador nestas circunstâncias, não ilustradas pela figura, são engatar a marcha na posição "RTO" e acelerar até que o avatar atinja o novo limiar - que neste caso corresponde ao valor 1 (hum). Neste ponto, a imagem do avatar voltará ao estado anterior e a luz do semáforo acesa voltará a ser a verde. A partir daí, o jogador deve engatar a marcha na posição "DRIVE" e acelerar para que a janela de congestionamento volte a crescer. Também neste caso, quanto mais rápido as ações forem realizadas, menor será o tempo de descarregamento do arquivo. 


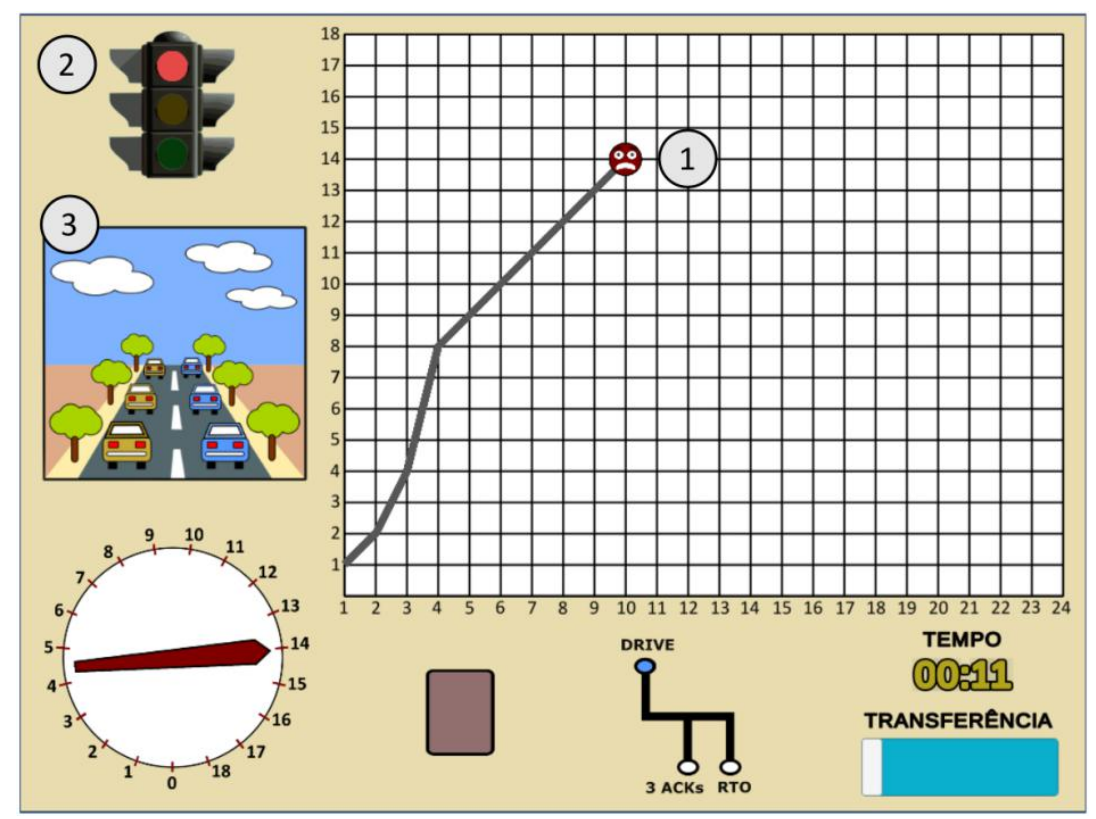

Figura 4. Perda percebida pela expiração do temporizador de retransmissão

\section{Validação}

Para validação do ConWin, foi utilizado o método EGameFlow, definido em Fu et al (2009). Este método toma como base o método GameFlow, definido em Sweetser e Wyeth (2006) para avaliação de jogos com base na Teoria do Fluxo proposta por Csikszentmihalyi (1990). Conforme ilustrado pela Tabela 1, o EGameFlow possui uma escala de oito categorias, cada qual contendo um conjunto de parâmetros. A nota de cada parâmetro é fornecida por cada avaliador utilizando uma escala Likert de sete pontos, que vai de "discordo fortemente" (1) até "concordo fortemente" (7).

Duas turmas da disciplina "Redes de Computadores" na UFERSA foram selecionadas no segundo semestre de 2019. Uma delas continha alunos do curso de Bacharelado em Ciência da Computação, modalidade presencial. A outra turma continha alunos do curso de Licenciatura em Computação, modalidade à distância. Em troca de pontos extras na disciplina, parte dos alunos de ambas as turmas concordaram em participar de um experimento composto por três etapas, precedidas da apresentação formal do conteúdo sobre o controle de congestionamento TCP:

- Etapa I: jogar o ConWin, sem limite de tempo. A comprovação desta etapa (útil especialmente com relação aos alunos de Licenciatura) era a visualização do nome do aluno no banco de dados mantido pelo jogo, juntamente com seu escore;

- Etapa II: realização de um pequeno teste contendo quatro questões da primeira variante descrita na Seção 3 - isto é, questões que pedem ao aluno identificar onde ocorrem as perdas de segmentos e de que forma elas são percebidas;

- Etapa III: preenchimento de um formulário contendo as questões da Tabela 1.

Tabela 1. Escala do EGameFlow.

\begin{tabular}{|c|c|l|ll|}
\hline Categoria & Parâmetro & \multicolumn{4}{|c|}{ Conteúdo } \\
\hline \multirow{3}{*}{ Concentração } & $\mathrm{C} 1$ & O jogo prende minha atenção? & \\
\cline { 2 - 5 } & $\mathrm{C} 2$ & Apresenta conteúdo que estimula minha atenção? & \\
\cline { 2 - 5 } & $\mathrm{C} 3$ & $\mathrm{~A}$ maioria das atividades está relacionada com a tarefa da \\
\hline
\end{tabular}


IX Congresso Brasileiro de Informática na Educação (CBIE 2020)

Anais do XXXI Simpósio Brasileiro de Informática na Educação (SBIE 2020)

\begin{tabular}{|c|c|c|}
\hline & & aprendizagem? \\
\hline & $\mathrm{C} 4$ & Nenhuma distração da tarefa é destacada? \\
\hline & $\mathrm{C} 5$ & No geral, consigo ficar concentrado no jogo? \\
\hline & C6 & Não sou distraído de tarefas nas quais deveria me concentrar? \\
\hline & $\mathrm{C} 7$ & Não sou sobrecarregado com tarefas que parecem sem importância? \\
\hline & $\mathrm{C} 8$ & A carga de trabalho do jogo é adequada? \\
\hline \multirow{10}{*}{ Desafios } & $\mathrm{H} 1$ & Aproveito o jogo sem ficar entediado ou ansioso? \\
\hline & $\mathrm{H} 2$ & Dificuldade é adequada? \\
\hline & $\mathrm{H} 3$ & Existem "dicas" que ajudam na tarefa? \\
\hline & $\mathrm{H} 4$ & Apresenta suporte on-line que ajuda na tarefa? \\
\hline & $\mathrm{H} 5$ & Apresenta vídeo ou áudio que ajudam na tarefa? \\
\hline & H6 & Minhas habilidades aumentam conforme o jogo avança? \\
\hline & $\mathrm{H} 7$ & Sou motivado pela melhora das minhas habilidades? \\
\hline & $\mathrm{H} 8$ & Os desafios aumentam conforme minhas habilidades aumentam? \\
\hline & H9 & Apresenta novos desafios em um ritmo adequado? \\
\hline & H10 & $\begin{array}{l}\text { Apresenta diferentes níveis de desafios que se adaptam aos diferentes } \\
\text { jogadores? }\end{array}$ \\
\hline \multirow{9}{*}{ Autonomia } & A1 & Tenho sensação de controle do menu? \\
\hline & A2 & Tenho sensação de controle sobre funções e objetos? \\
\hline & A3 & $\begin{array}{l}\text { Tenho sensação de controle sobre as interações entre funções e } \\
\text { objetos? }\end{array}$ \\
\hline & A4 & Não é possível cometer erros que impedem o avanço do jogo? \\
\hline & A5 & Posso me recuperar de qualquer erro cometido? \\
\hline & A6 & Sinto que posso usar quaisquer estratégias? \\
\hline & A7 & Tenho sensação de controle e impacto sobre o jogo? \\
\hline & A8 & Sei o próximo passo no jogo? \\
\hline & A9 & Tenho sensação de controle sobre o jogo? \\
\hline \multirow{5}{*}{$\begin{array}{l}\text { Clareza dos } \\
\text { Objetivos }\end{array}$} & G1 & Objetivos gerais apresentados no início do jogo? \\
\hline & $\mathrm{G} 2$ & Objetivos gerais apresentados claramente? \\
\hline & G3 & Objetivos intermediários apresentados no local apropriado? \\
\hline & G4 & Objetivos intermediários apresentados claramente? \\
\hline & G5 & Eu entendo os objetivos do aprendizado através do jogo? \\
\hline \multirow{6}{*}{ Feedback } & F1 & Recebo feedback do meu progresso no jogo? \\
\hline & $\mathrm{F} 2$ & Recebo feedback imediato das minhas ações? \\
\hline & F3 & Sou notificado sobre novas tarefas imediatamente? \\
\hline & F4 & Sou notificado sobre novos eventos imediatamente? \\
\hline & F5 & $\begin{array}{l}\text { Recebo informação sobre sucesso ou falha de objetivos intermediários } \\
\text { imediatamente? }\end{array}$ \\
\hline & F6 & Recebo informação sobre o meu status, como nível ou pontuação? \\
\hline \multirow{7}{*}{ Imersão } & $\mathrm{I} 1$ & Esqueço do tempo enquanto jogo? \\
\hline & $\mathrm{I} 2$ & Esqueço das coisas ao meu redor enquanto jogo? \\
\hline & $\mathrm{I} 3$ & Esqueço dos problemas do dia-a-dia enquanto jogo? \\
\hline & I4 & Sinto uma noção de tempo alterada? \\
\hline & I5 & Posso ficar envolvido com o jogo? \\
\hline & I6 & Me sinto emocionalmente envolvido com o jogo? \\
\hline & $\mathrm{I} 7$ & Me sinto visceralmente envolvido com o jogo? \\
\hline \multirow{6}{*}{$\begin{array}{l}\text { Interação } \\
\text { Social }\end{array}$} & $\mathrm{S} 1$ & Me sinto cooperativo com outros colegas? \\
\hline & $\mathrm{S} 2$ & Colaboro muito com outros colegas? \\
\hline & S3 & Cooperação no jogo auxilia no aprendizado? \\
\hline & $\mathrm{S} 4$ & O jogo suporta interação social (chats, etc...)? \\
\hline & S5 & O jogo suporta comunidades dentro do jogo? \\
\hline & S6 & O jogo suporta comunidades fora do jogo? \\
\hline \multirow{4}{*}{$\begin{array}{l}\text { Melhoria do } \\
\text { Conhecimento }\end{array}$} & K1 & O jogo melhora meu conhecimento? \\
\hline & $\mathrm{K} 2$ & Capto as ideias básicas do conteúdo apresentado? \\
\hline & $\mathrm{K} 3$ & Tento aplicar o conhecimento no jogo? \\
\hline & K4 & O jogo motiva o jogador a integrar o conteúdo apresentado? \\
\hline
\end{tabular}




\begin{tabular}{|l|l|l|}
\hline & K5 & Quero saber mais sobre o conteúdo apresentado? \\
\hline
\end{tabular}

Apenas os alunos que cumpriram as três etapas foram considerados no estudo na turma de Bacharelado, este número correspondeu a 5 de 10 alunos. Na turma de licenciatura, a 15 de 75. Considerando que a distribuição de frequência das respostas obtidas para cada parâmetro na Tabela 1 difere da Normal, e de forma a desconsiderar discrepâncias, optou-se por utilizar a mediana como estatística descritiva para análise das respostas. A Figura 5 ilustra as medianas dos parâmetros de cada categoria para ambas as turmas. Para cada categoria, optou-se por utilizar a média dentre os parâmetros de cada categoria como estatística para descrever o desempenho do jogo naquela categoria. A Figura 6 ilustra o resultado obtido para ambas as turmas. Em termos gerais o jogo é bem avaliado do ponto de vista dos alunos em quase todas as categorias, e não se percebe discordâncias significativas entre as turmas com relação às médias de cada categoria. De particular interesse é a categoria "Melhoria do Conhecimento", haja vista ser ConWin um jogo educativo. As médias obtidas na turma presencial $(5,8)$ e à distância $(6,0)$ sugerem que os alunos têm a percepção de que o jogo os auxilia no aprendizado do controle de congestionamento TCP. Por outro lado, a categoria na qual o jogo é pior avaliado é a categoria "Interação Social". Embora as média obtidas nas duas turmas sejam bastante divergentes $(2,0$ e 4,8$)$, neste particular acredita-se que as respostas da turma presencial se encontram mais próximas da realidade. De fato, ConWin não é um jogo multiplayer e a única forma de um jogador saber quem além dele o jogou é o ranking com as cinco melhores pontuações.

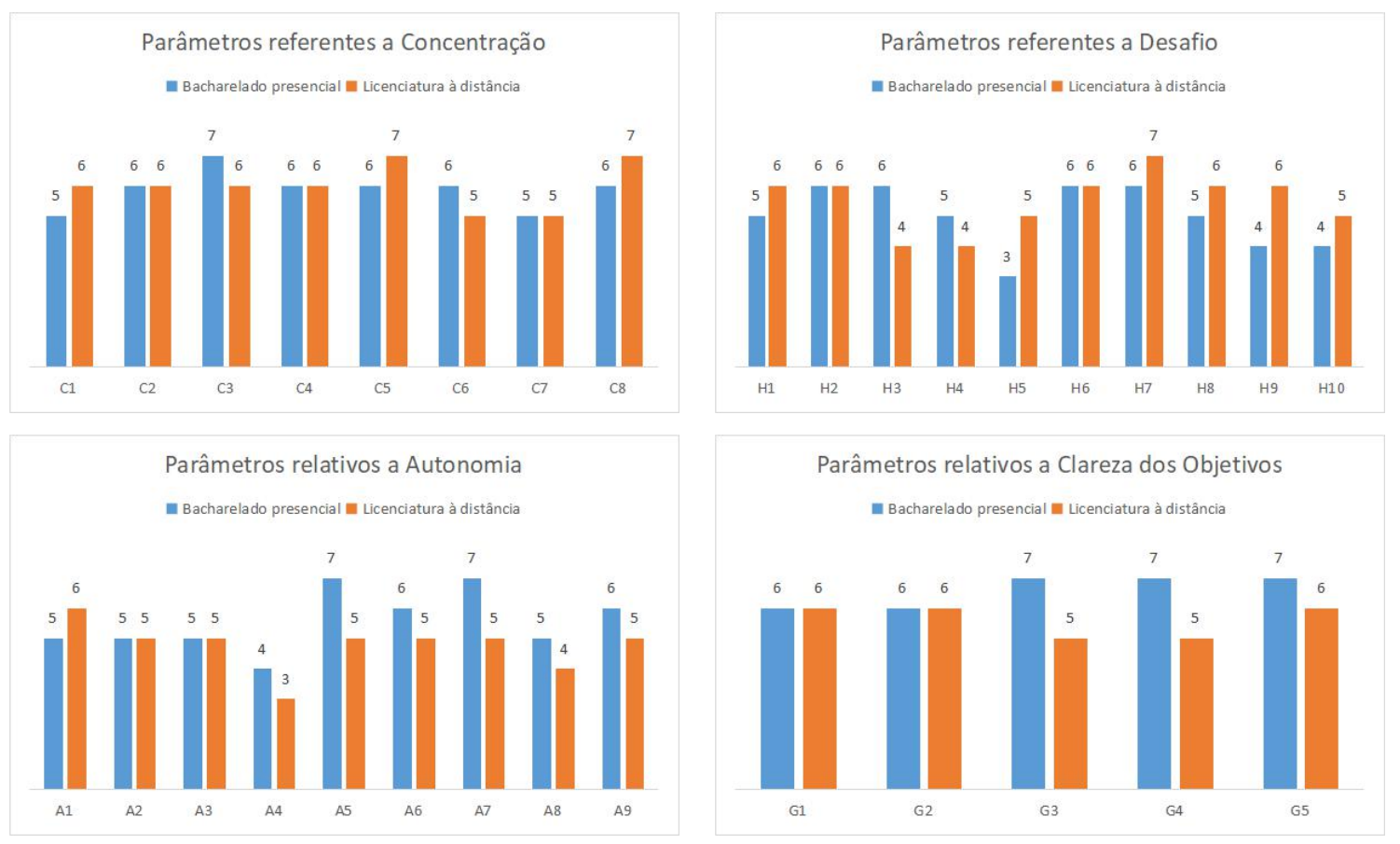



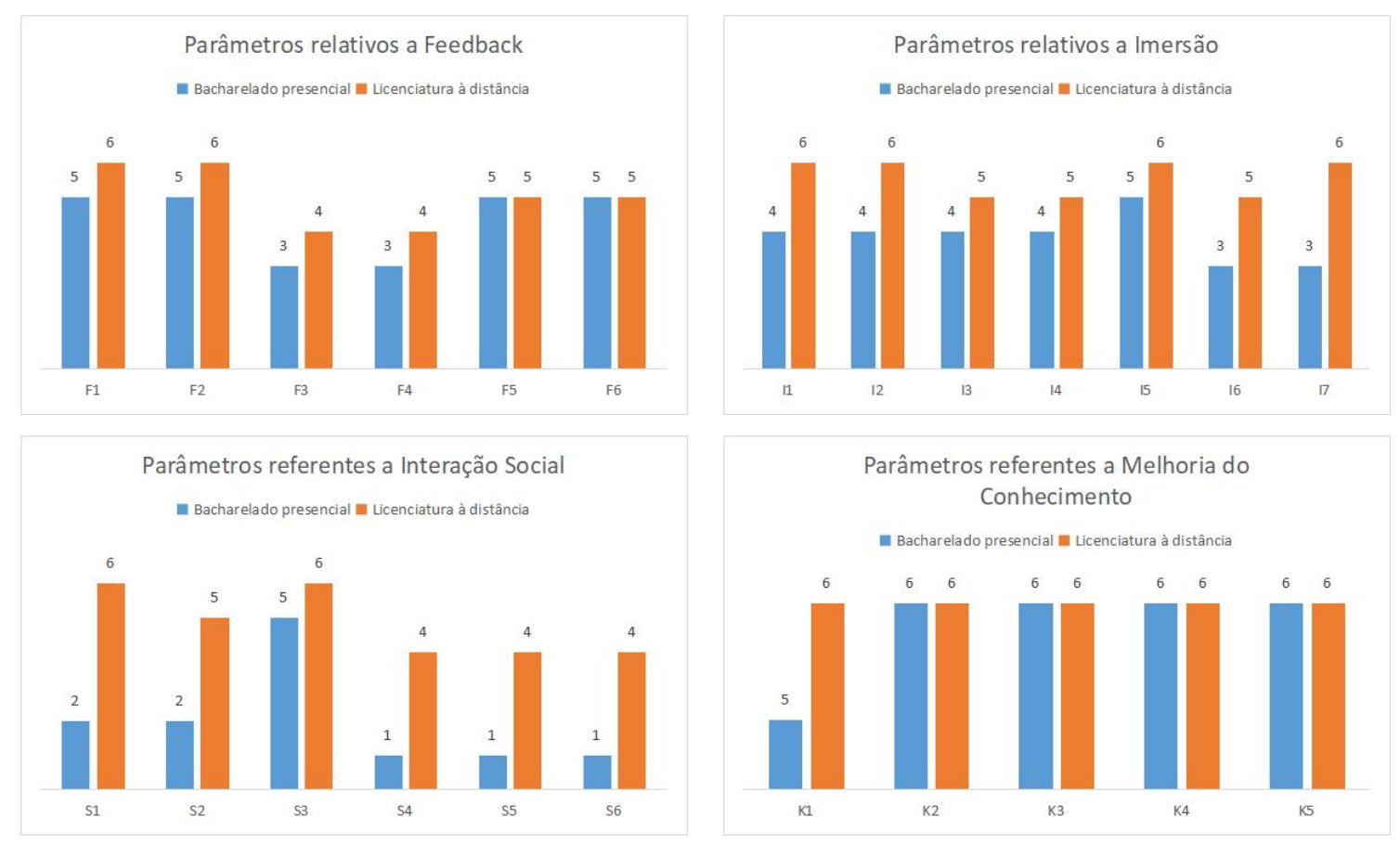

Figura 5. Mediana dos parâmetros de cada categoria para ambas as turmas

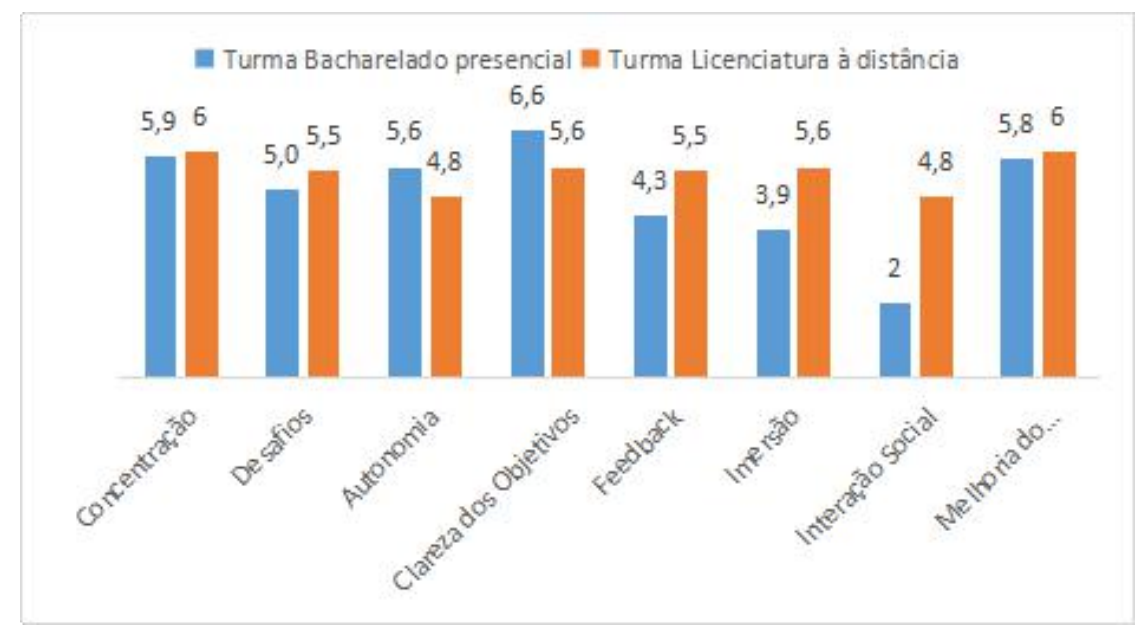

Figura 6. Médias das categorias para ambas as turmas

\section{Considerações finais}

Erros recorrentes em questões relacionadas ao controle de congestionamento TCP têm sido observados em algumas turmas da disciplina "Redes de Computadores" na UFERSA. Esta constatação impulsionou a pesquisa por métodos alternativos para o aprendizado daquele conteúdo. Dentre eles, estava o projeto e desenvolvimento de um jogo sério. Neste sentindo, pesquisas adicionais não encontraram nenhum jogo existente que contemplasse especificamente o controle de Congestionamento TCP. Surgiu assim o ConWin.

O jogo desenvolvido tem como pano de fundo a transferência de um arquivo pelo TCP tendo como elemento lúdico a condução de um veículo. Neste contexto, sob condições de congestionamento que ocorrem aleatoriamente, as marchas do veículo precisam ser adequadamente trocadas para que ele se desloque. A habilidade do 
condutor na realização desta troca é o principal fator contribuinte para que o arquivo seja integralmente transferido. Um ranking contendo os cinco melhores tempos foi projetado para estimular a competitividade entre os alunos.

Para validar o ConWin, um experimento foi conduzido com voluntários de duas turmas: $50 \%$ dos alunos de uma turma de Bacharelado em Ciência da Computação (modalidade presencial) e $20 \%$ de uma turma de Licenciatura em Computação (modalidade à distância). É provável que os percentuais certamente seriam maiores se a participação fosse de caráter compulsório, ou se os pontos extras fossem maiores. Foi usada a metodologia EGameFlow para avaliar o jogo sob a perspectiva do usuário, e os resultados foram particularmente favoráveis, especialmente no que diz respeito à percepção de melhoria do aprendizado do conteúdo - algo que é corroborado pela alta taxa de acertos no teste aplicado aos alunos após terem jogado.

\section{Referências}

Allman, M., Paxson, V. e Stevens, W. (1999). "TCP Congestion Control”. RFC 2581. Disponível em https://www.ietf.org/rfc/rfc2581.txt;

Battistella, P., \& Gresse von Wangenheim, C. (2016). "Games for teaching computing in higher education - A systematic review", IEEE Technology and Engineering Education, 9(1), páginas 8-30;

Csikszentmihalyi, M. (1990) "Flow: The Psychology of Optimal Experience", Harper \& Row.

Fu, F., Su, R. e Yu, S. (2009) "EGameFlow: A scale to measure learners' enjoyment of e-learning games", Computers \& Education, Volume: 52, edição: 1, páginas 101-112. Doi:10.1016/j.compedu.2008.07.004;

Hays, R. (2005) "The Effectiveness of Instructional Games: a Literature Review and Discussion". Technical Report 2005-004. Naval Air Warfare Center Training System Division. Disponível em http://www.dtic.mil/dtic/tr/fulltext/u2/a441935.pdf;

Michael, D. e Chen, S. (2005) "Serious Games: Games That Educate, Train, and Inform", Course Technology PTR;

NS Simulator Projects (2018) "NS2 TCP Congestion Control: How to Simulate TCP Congestion Control Using NS-2”. Disponível em http://ns2simulator.com/ns2-tcpcongestion-control/;

Sweetser, P. e Wyeth, P. (2006) "GameFlow: A Model for Evaluating Player Enjoyment in Games ", ACM Computers in Entertainment 3-3, páginas 1-24. Doi: 10.1145/1077246.1077253;

Vogel, Jennifer J., Vogel, David S., Cannon-Bowers, Jan, Bowers, Clint A., Muse, Kathryn e Wright, Michelle (2006) "Computer Gaming and Interactive Simulations for Learning: A Meta-Analysis". Journal of Educational Computing Research, Volume: 34 edição: 3, páginas: 229-243;

Zabala, A. (1998) “A Prática Educativa: Como Ensinar”. Artmed; 